\title{
Avaliação do método de obtenção de scaffolds quitosana/curcumina sobre a estrutura, morfologia e propriedades térmicas
}

\author{
Evaluation of the obtaining method of chitosan/ \\ curcumin scaffolds on the structure, \\ morphology and thermal properties
}

\author{
Milena Costa Silva ${ }^{1}$, Imarally Nascimento ${ }^{1}$, \\ Vitor de Souza Ribeiro ${ }^{1}$, Marcus Vinicius Lia Fook ${ }^{1}$
}

\begin{abstract}
${ }^{1}$ CERTBIO, Unidade Acadêmica de Engenharia de Materiais, Universidade Federal de Campina Grande, Rua Aprígio Veloso, 882, Bodocongó, CEP 58109-970, Campina Grande, Paraíba, Brasil

e-mail: milecost@hotmail.com; imarally.souza@hotmail.com; marcusvinicius@dema.ufcg.edu.br
\end{abstract}

\begin{abstract}
RESUMO
Pesquisas tem sido realizada com objetivo de combinar propriedades dos materiais com a finalidade de melhorar o processo de regeneração. Portanto scaffolds como sistemas de liberação controlada de fármacos tem sido estudado a fim de proporcionar o crescimento do tecido ao mesmo tempo que a região esteja sendo tratada. Diante disso, essa pesquisa tem como objetivo desenvolver scaffolds de quitosana e avaliar a inserção do fármaco curcumina por meio dos métodos de reação de solução e adsorção visando obter um sistema quitosana/curcumina para liberação controlada do fármaco. Os scaffolds foram produzidos pelo método de agregação de esferas, onde as esferas foram inicialmente obtidas a partir do gotejamento da solução de quitosana e quitosana/curcumina em solução de sulfato de sódio (5\%) e posteriormente agregadas pela solução de gelatina (5\%). Foram realizadas as caracterizações de espectroscopia no infravermelho com transformada de Fourier (FTIR), microscopia ótica (MO), microscopia eletrônica de varredura (MEV) e calorimetria exploratória diferencial (DSC). Por FTIR sugeriu-se a interação da quitosana com a curcumina. A partir das avaliações morfológicas por MO e MEV foi possível identificar o fármaco no interior das estruturas pelos dois métodos utilizado. E por DSC observou-se para amostra de quitosana/curcumina o desaparecimento do pico de fusão característico da curcumina, indicando assim que a curcumina foi encapsulada na quitosana no estado amorfo, o que provavelmente ocasionará uma liberação mais lenta do fármaco. Dessa forma, constatou-se que as estruturas obtidas são promissoras para o estudo de liberação controlada de fármaco.
\end{abstract}

Palavras-chave: Curcumina, Quitosana, Scaffolds.

\begin{abstract}
Researches have been conducted in order to match material properties to improve the regeneration process. Thereby, scaffolds as controlled drug delivery systems have been studied in order to enhance the obtained structure by providing tissue growth while the region is being treated. Thus, this research aims to develop scaffolds of chitosan, and avaluatinh the insertion of curcumin drug by the methods of , solutions reaction and adsorption, aiming at obtaining a chitosan/curcumin for controlled drug release system. The scaffolds were produced by beads aggregation method, in which the beads were originally obtained from the dropping of chitosan solution and chitosan / curcumin in sodium sulphate solution (5\%) and then attached by the gelatin solution (5\%). The following characterizations were performed: Fourier Transform Infrared Spectroscopy (FTIR), Optical Microscopy (OM), Scanning Electron Microscopy (SEM) and Differential Scanning Calorimetry (DSC). By FTIR analysis, it was possible to verify the likely interaction of chitosan with curcumin. From the morphological analysis by OM and SEM it was possible to identify the drug inside the structures by both methods. DSC analysis showed the total disappearance of the characteristic melting peak of curcumin, thus indicating that curcumin has been encapsulated in chitosan in the amorphous state,
\end{abstract}


which is likely to cause a slower release of the drug. Thus, it was found that the obtained structures are promising for the study of controlled drug release.

Keywords: Curcumin, Chitosan, Scaffolds.

\section{INTRODUÇÃO}

Scaffolds para a engenharia de tecidos tem recebido cada vez mais atenção, na área médica e biomédica devido à sua capacidade de permitir que células humanas saudáveis possam crescer em sua estrutura, in vitro ou in vivo, para efeitos de reparação, restauração ou manutenção das funções de tecidos danificados ou doentes [1]. Como definição pode-se dizer que, os scaffolds são sólidos tridimensionais celulares que fornecem o suporte necessário para a fixação, proliferação, diferenciação e orientação das células, a fim de permitir o crescimento do tecido semelhante. Estas estruturas mimetizam o comportamento de uma matriz extracelular para proporcionar o meio biomecânico apropriado para a diferenciação celular e o crescimento do tecido $[2,3]$.

Scaffolds para engenharia de tecidos são, geralmente, feitos de materiais biocompatíveis, biodegradáveis e bioabsorvíveis com estruturas porosas e interligadas para transporte de nutrientes e resíduos. A quitosana, é um exemplo desse tipo de material, sendo muito utilizado para a fabricação de scaffolds na reparação de tecidos [1,4,5]. A quitosana é um copolímero composto por N-acetil-2-amino-2-desoxi-D-glucopiranose e 2amino-2-desoxi-D-glucopiranose, onde os dois tipos de unidades de repetição estão ligadas por $(1 \rightarrow 4)-\beta$ glicosídica, estas unidades estão distribuídas em diferentes graus, dependendo das porções acetiladas. A cadeia polimérica da quitosana é do tipo linear e assim como a maioria dos polissacarídeos e proteínas, a quitosana é um termoplástico, pois é constituído de cadeias poliméricas individuais que são mantidas juntas por ligações relativamente fracas, como ligações dipolo-dipolo e forças de Van der Waals, podendo ser processado por técnicas usuais e ser dissolvido em solventes, formando nanofibras [6], nanopartículas [7], micropartículas [8], membranas [9], géis [10] e scaffolds [11,12].

Nos últimos anos pesquisas tem sido desenvolvida na utilização da quitosana como matriz para a liberação controlada de fármaco [13, 14]. A administração do fármaco via sistemas de liberação controlada é vantajosa porque podem ser adaptadas para o perfil de liberação desejada, e podem até mesmo permitir a liberação em regiões específicas do organismo. O termo "liberação controlada" implica na predição e na reprodutibilidade da cinética de liberação de um fármaco, atuando dentro da faixa terapêutica do fármaco [15].

Dentro deste contexto tem-se a curcumina que é um fármaco bastante pesquisado por apresentar propriedades bem satisfatórias, sendo antioxidante, anti-inflamatório, antibacteriana, antiparasitários, antimalárica e anticancerígenas. É comercialmente disponível como um extrato de raízes de Curcuma longa, onde o seu conteúdo é estimado na soma do teor dos curcuminóides, com tipicamente $77 \%$ de curcumina, $17 \%$ de demetoxicurcumina e $6 \%$ de bis-demetoxicurcumina. Apresentando uma composição atômica $\mathrm{C}_{21} \mathrm{H}_{20} \mathrm{O}_{6}$ com massa molecular de $368,39 \mathrm{~g} / \mathrm{mol}$ e ponto de fusão de $183^{\circ} \mathrm{C}$. Sendo de natureza hidrofóbica, a curcumina é insolúvel em soluções aquosas, mas solúvel em solventes orgânicos tais como dimetilsulfóxido (DMSO), acetona, metanol e etanol, sendo que o máximo de absorção $\left(\lambda_{\max }\right)$ de curcumina ocorre em metanol por volta de $430 \mathrm{~nm}$. Para utilizar as atividades farmacêuticas da curcumina e superar a sua fraca disponibilidade no local de ação no corpo, outras formas de sua utilização, têm sido desenvolvidas tais como; a utilização de micelas, complexos fosfolipídios, ciclodextrina, lipossomas, nanopartículas, macromoléculas, hidrogéis $[16,17,18]$.

Portanto, esta pesquisa teve como objetivo principal desenvolver scaffolds de quitosana e avaliar a inserção do fármaco curcumina por meio dos métodos de solução e adsorção visando obter um sistema quitosana/curcumina para liberação controlada do fármaco.

\section{MATERIAIS E MÉTODOS}

Para a realização desta pesquisa foram utilizados os seguintes materiais: quitosana em pó de médio peso molecular, com grau de desacetilação entre 75 - 85\%; Curcumina Longa, Tampão de Fosfato Salino (PBS) e a Gelatina Porcina tipo A, todos adquiridos da Sigma-Aldrich. O sulfato de sódio adquirido da Nuclear ( $\left.\mathrm{Na}_{2} \mathrm{SO}\right)$; ácido acético glacial, P.A. $\left(\mathrm{C}_{2} \mathrm{H}_{4} \mathrm{O}_{2}\right)$, peso molecular $60.05 \mathrm{~g} / \mathrm{mol}$, adquirido da Sigma-Aldrich e o metanol, adquirido da Neon.

A solução de quitosana $(2 \% \mathrm{~m} / \mathrm{v})$ foi preparada por meio da dissolução do polímero na forma de pó com uma solução de ácido acético $(1 \%$ v/v), com auxílio de um agitador mecânico, a temperatura ambiente por 24 
horas. Posteriormente as esferas de quitosana foram obtidas a partir do método de gelificação ionotrópica, que parte do gotejamento da solução de quitosana por meio de uma seringa de $20 \mathrm{~mL}$ acoplada com uma agulha de dimensões $0,45 \mathrm{~mm}$ x 13mm (26G x 1/2”). O gotejamento ocorreu com o auxílio de uma bomba de infusão, com razão de $26 \mathrm{~mL} / \mathrm{h}$ em uma solução coagulante de sulfato de sódio $(5 \% \mathrm{~m} / \mathrm{v})$, onde as esferas ficaram imersas por 1 hora. Em seguida as esferas foram lavadas com uma solução de PBS até neutralizar o $\mathrm{pH}$.

Para a introdução do fármaco na quitosana foram utilizados dois métodos. O primeiro método baseou-se na reação das soluções de quitosana e curcumina, denotado como a amostra quitosana/curcumina. Nesse método o pó de curcumina, foi dissolvido em metanol $(10 \mathrm{mg} / \mathrm{mL})$ permanecendo 3 horas em banho ultrassom. Em seguida, a solução de curcumina $(10 \mathrm{~mL})$ foi incorporada à solução de quitosana $(50 \mathrm{~mL})$ previamente obtida, na relação de 1:5 (curcumina:quitosana), sob agitação mecânica constante por 30 minutos.

No segundo método as esferas de quitosana (150mg) previamente obtidas por gelificação ionotrópica, foram adicionadas em $25 \mathrm{~mL}$ de solução de curcumina $(10 \mathrm{mg} / \mathrm{mL})$, protegidas da luz por meio da vedação do becker com papel alumínio, por 24 horas, sob agitação mecânica constante de 80 RPM, em temperatura ambiente. Após o tempo de contato com a solução as esferas foram filtradas e o excesso de fármaco presente na superfície da esfera foi retirado, com a lavagem das esferas em água destilada. Obtendo-se assim o sistema quitosana/curcumina (adsorção) na forma de esferas.

Para a obtenção dos scaffolds as esferas de quitosana; quitosana/curcumina e quitosana/curcumina (adsorção) foram acondicionadas em tubos falcons contendo aproximadamente $20 \mathrm{~mL}$ de esferas, que foram calculadas a partir da utilização do volume de $20 \mathrm{~mL}$ na seringa. Adicionando-se em seguida a solução de gelatina porcina (5\%), para ocorrer a adesão entre as partículas. Posteriormente foram congeladas, em um freezer (Brastemp clear - 410) a aproximadamente $-10^{\circ} \mathrm{C}$ e liofilizadas, em um liofilizador (L108, aço inox AISI304 - LIOTOP) por 48 horas.

As amostras foram submetidas a técnica de espectroscopia na região do infravermelho com transformada de Fourier (FTIR), em temperatura ambiente e o equipamento utilizado foi o Spectrum 400 da Perkin Elmer.

Para realização das análises morfológicas foram utilizadas as técnicas de Microscopia Ótica e Microscopia Eletrônica de Varredura onde os scaffolds de quitosana, quitosana/curcumina e quitosana/curcumina (adsorção), foram analisados por meio das imagens da estrutura externa e da superfície de fratura. Utilizou-se um Microscópio Óptico Hirox de reflexão e transmissão com acessórios 2D e aumentos que variam de 50 a 400X, acoplado a uma estação de análise de imagens. Também foi utilizado o Microscópio Eletrônico de Varredura de bancada, modelo TM-1000, marca Hitachi, com aumento de 10000x, profundidade de foco de $1 \mathrm{~mm}$, resolução de $30 \mathrm{~nm}, 15 \mathrm{KV}$, baixo vácuo e pressão variada (1 a 270 $\mathrm{Pa}$ ), sem recobrimento metálico. Com auxílio do programa ImageJ, foi possível verificar os tamanhos dos poros das imagens a partir da média de seis amostras $(\mathrm{n}=6)$.

Para a análise de Calorimetria Exploratória Diferencial utilizou-se o equipamento DSC 8500 Perkin Elmer, com o objetivo de observar as transições de fases, ocorridas na primeira curva de aquecimento. Utilizou-se para a realização do ensaio atmosfera de nitrogênio $50 \mathrm{~mL} \mathrm{~min}^{-1}$, com taxa de aquecimento de $10^{\circ} \mathrm{C} /$ min em cadinho de alumínio. Onde as entalpias de fusão das amostras foram obtidas a partir do cálculo da área dos picos obtidos diretamente no gráfico.

\section{RESULTADOS E DISCUSSÃO}

No espectro da quitosana, as principais bandas observadas foram: as bandas nas regiões de 890 e $1140 \mathrm{~cm}^{-1}$ atribuídas ao alongamento C-O-C; 1020 a $1100 \mathrm{~cm}^{-1}$ amino (CN) correspondente as aminas alifáticas; as regiões em 1065 e $1022 \mathrm{~cm}^{-1}$ refere-se ao grupo (C-O); a deformação axial de grupos entre 1323 a $1379 \mathrm{~cm}^{-1}$ e deformação angular simétrica do $\mathrm{CH}_{3}$ em $1379 \mathrm{~cm}^{-1}$ conforme também reportado por Beppu et al., 1999 e Souza et al., 2010 [19, 20]. Na região da banda $1411 \mathrm{~cm}^{-1}$ e $1599 \mathrm{~cm}^{-1}$ a vibração é atribuída à deformação do grupo amina (NH); e amida em 1600-1670 $\mathrm{cm}^{-1}$ e em $1568 \mathrm{~cm}^{-1}$ tem-se a banda referente ao grupo amino $\left(\mathrm{NH}_{2}\right)$, em $1380 \mathrm{~cm}^{-1}$ tem-se a região corresponde a ao grupo $(\mathrm{CH})$; em $2900 \mathrm{~cm}^{-1}$ a vibração é atribuída ao estiramento $\mathrm{CH}$. A região localizada entre 3665 a $3000 \mathrm{~cm}^{-1}$ é atribuída as vibrações de estiramento dos grupos $\mathrm{OH}$ e $\mathrm{NH}$.

No FTIR da curcumina foi possível observar a região de vibração em $3500 \mathrm{~cm}^{-1}$, que podem ser atribuídos a vibração de alongamento do grupo fenólico $(\mathrm{OH})$. Além disso, bandas de absorção nítidas em $1605 \mathrm{~cm}^{-1}$ são correspondentes às vibrações do alongamento do anel de benzeno da curcumina. A banda 1510 
$\mathrm{cm}^{-1}$ ocorre devido a vibração de estiramento de C-C do anel de benzeno. A banda em $1463 \mathrm{~cm}^{-1}$ correspondente ao modo de vibração de C-O alongamento dos grupos álcool e fenol. Em $1426 \mathrm{~cm}^{-1}$ a flexão da vibração do grupo (CH) ligado ao anel de benzeno da curcumina. Na região de $1272 \mathrm{~cm}^{-1}$ tem-se o modo de vibração de C - O. A região de 1025 a $840 \mathrm{~cm}^{-1}$, corresponde ao estiramento do grupo C - O - C. As bandas na região de 962 , 815 e $719 \mathrm{~cm}^{-1}$ foram atribuídas às vibrações de flexão da ligação $\mathrm{CH}$ de grupos alcenos $\left(\mathrm{RCH}=\mathrm{CH}_{2}\right.$ ), estas bandas também foram observadas por Sampath et al., 2014 [21], quando estudaram a regiões de vibrações da curcumina em pó.

A partir do gráfico de FTIR do scaffold de quitosana/curcumina (Fig. 1) foi possível observar que as bandas apresentam uma menor intensidade, quando comparada com as bandas características da curcumina, e regiões com maior intensidade quando comparadas com o gráfico da esfera de quitosana. Provavelmente isto ocorreu devido ao fármaco estar localizado no interior das esferas. Para o gráfico do FTIR para o scaffold de quitosana/curcumina (adsorção) (Fig. 1), verifica-se o espectro semelhante ao do scaffold de quitosana/curcumina obtida pela reação das soluções, porém, observa-se uma maior intensidade de transmitância de todas as bandas presentes na amostra quitosana/curcumina (adsorção).

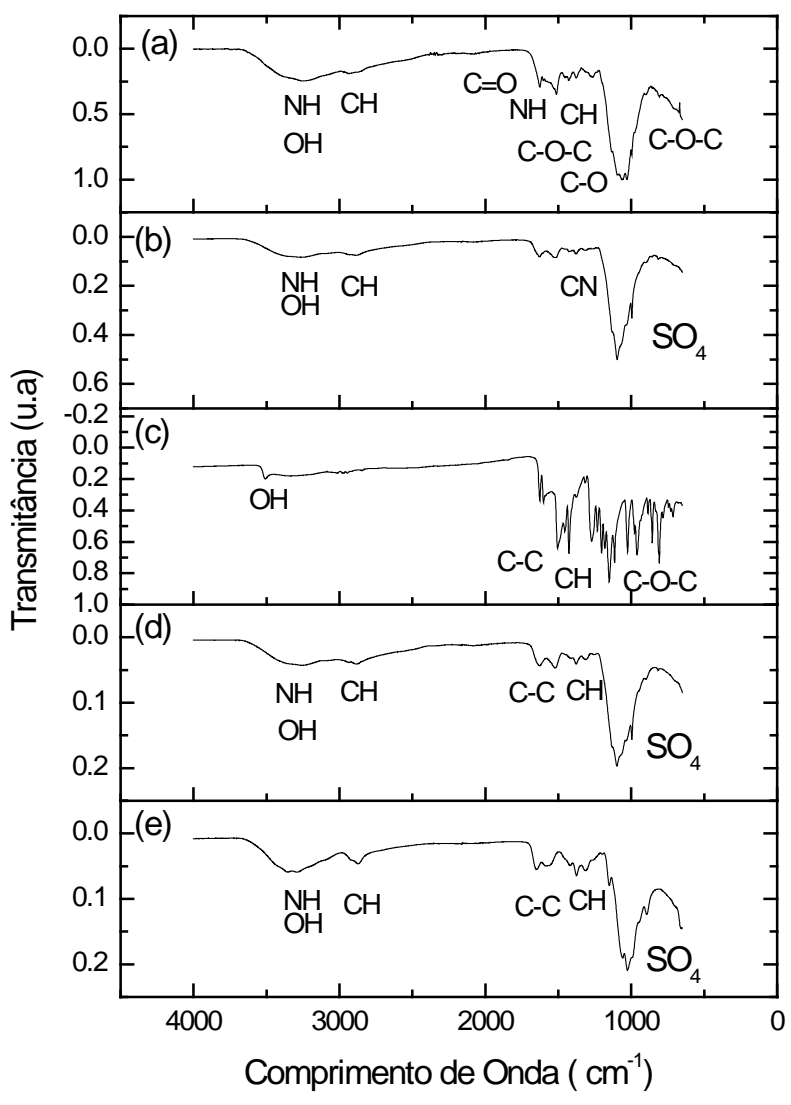

Figura 1: FTIR da (a) quitosana, (b) scaffold quitosana, (c) curcumina, (d) scaffold quitosana/curcumina e (e) scaffold quitosana/curcumina (adsorção).

Em ambas as amostras observa-se a região de $1025 \mathrm{~cm}^{-1}$ correspondente à presença do grupo cetona da curcumina, em $1620 \mathrm{~cm}^{-1}$ tem-se a banda referente ao estiramento $\mathrm{C}=\mathrm{O}$ da cetona, a região em $1420 \mathrm{~cm}^{-1}$ refere-se ao estiramento $\mathrm{C}=\mathrm{C}$ do anel alifático, a banda em $1380 \mathrm{~cm}^{-1}$ refere-se ao estiramento dos grupos $\mathrm{CH}_{3}$ presentes na estrutura da curcumina. Observa-se também a presença do grupo amina (que foi deslocado) pertencente à quitosana na região entre 1485 e $1577 \mathrm{~cm}^{-1}$, corroborando com as regiões de vibrações encontradas por Parize et al., 2009 [22]. Os deslocamentos de bandas, quando comparadas com o espectro da quitosana e da curcumina, sugere a existência de interações físicas entre a quitosana e o fármaco. De acordo com Anitha et al., 2011 [23], a interação entre os grupos cetona da curcumina e os grupos amina protonados 
da quitosana, causaram provavelmente o carreamento do fármaco no polímero.

Os scaffolds de quitosana, quitosana/curcumina e quitosana/curcumina (adsorção), foram analisados por microscopia ótica por meio das imagens da estrutura superfície de fratura e externa dos sistemas. Na estrutura superfície de fratura dos scaffolds de quitosana Fig. 2(a) e quitosana/curcumina, Fig. 2(b) tem-se uma estrutura interna com característica esponjosa, formada provavelmente pelo processo de liofilização. Para a amostra de quitosana/curcumina (adsorção), Fig. 2(c), verifica-se estruturas com aspecto solto, onde se verifica que algumas esferas permaneceram com o formato inicial, porém não apresentam boa aderência umas com as outras. Observa-se também heterogeneidade na morfologia das partículas e dos poros.

A partir das imagens da estrutura externa (Fig. 2(d), (e) e (f)) das amostras é possível observar nas estruturas a presença da gelatina, que atua como uma rede interconectando uma esfera a outra e envolvendoas com uma fina camada, dando resistência ao scaffold formado. Verifica-se também que os scaffolds de quitosana/curcumina obtida pela reação de soluções (Fig. 2(e)), apresentam uma maior homogeneidade com poros mais esféricos, haja visto, que a adição da curcumina, pelo método de reação de soluções, alterou a morfologia deixando as esferas mais homogênea. Na amostra de quitosana/curcumina obtidas pelo método de adsorção (Fig. 2(f)), tem-se uma morfologia mais irregular, observa-se distorção nas esferas do scaffold.


Figura 2: Imagens de microscopia óptica da superfície de fratura dos scaffolds 40X, (a) quitosana (b) quitosana/curcumina (c) quitosana/curcumina-(adsorção), da região externa dos scaffolds (d) quitosana (e) quitosana/curcumina (adsorção) e (f) quitosana/curcumina (adsorção).

A partir da microscopia eletrônica dos scaffolds de quitosana, Fig. 3(a), tem-se o detalhe da interface gerada pela ligação de uma esfera a outra por meio da solução de gelatina. Observa-se ainda na Fig. 3 (b), poros de tamanhos variados. Averiguou-se também uma porcentagem maior de poros com dimensão de 30$60 \mu \mathrm{m}$, com tamanho de poros mais regulares, apresentando formato hexagonal. Na amostra de quitosana/curcumina obtida pela mistura de soluções (Fig. 3(c)), foi observada a interconexão de uma esfera a outra, esta ligação entre as partículas foi obtida por meio da solução de gelatina, que atua ao redor das esferas resultando assim na união destas, desenvolvendo assim a estrutura tridimensional. Verificam-se também vários poros dispersos nas esferas com diâmetro médio de 25,40 $\mu \mathrm{m} \pm 3,03(\mathrm{n}=6)$. Provavelmente o surgimento desses poros ocorreu devido a evaporação da solução alcoólica utilizada na preparação da solução de curcumina. A presença destes poros poderá ocasionar uma liberação mais rápida da curcumina (Fig. 3(d)).

Na região superfície de fratura da Fig. 3(d) observa-se que a estrutura apresenta poros irregulares e heterogêneos.

As Fig. 3(e) e (f) apresentam as esferas de quitosana/curcumina obtidas pelo método de adsorção, a (Fig. $3(e))$ mostra a parte externa da estrutura e detalha a interligação das esferas pela gelatina, porém tem-se que a região de interligação ocorre de forma diferente, há uma região mais espessa de gelatina ligando as esferas.

Na Fig. 3(f) é possível observar a partir do corte da secção transversal a falta aderência entre as partículas, o que poderá ocasionar uma menor resistência a compressão da estrutura, onde estas apresentam 
superfície bastante áspera, sendo também possível verificar a presença de pontos mais escuros na superfície de corte das esferas relacionado à distribuição do fármaco, conforme visto pela Microscopia Ótica.

A Figura 3 apresenta a morfologia obtida por microscopia eletrônica dos scaffolds de quitosana (Fig. 3(a) e (b)), quitosana/curcumina obtida pela mistura de soluções (Fig. 3(c) e (d)) e pelo método de adsorção (Fig. 3(e) e (f)).
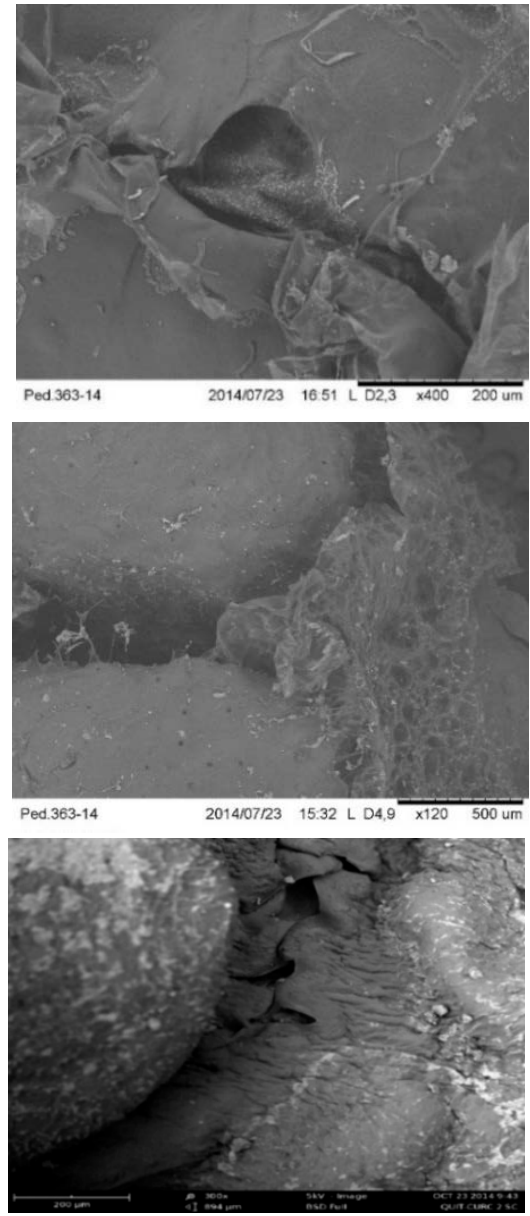
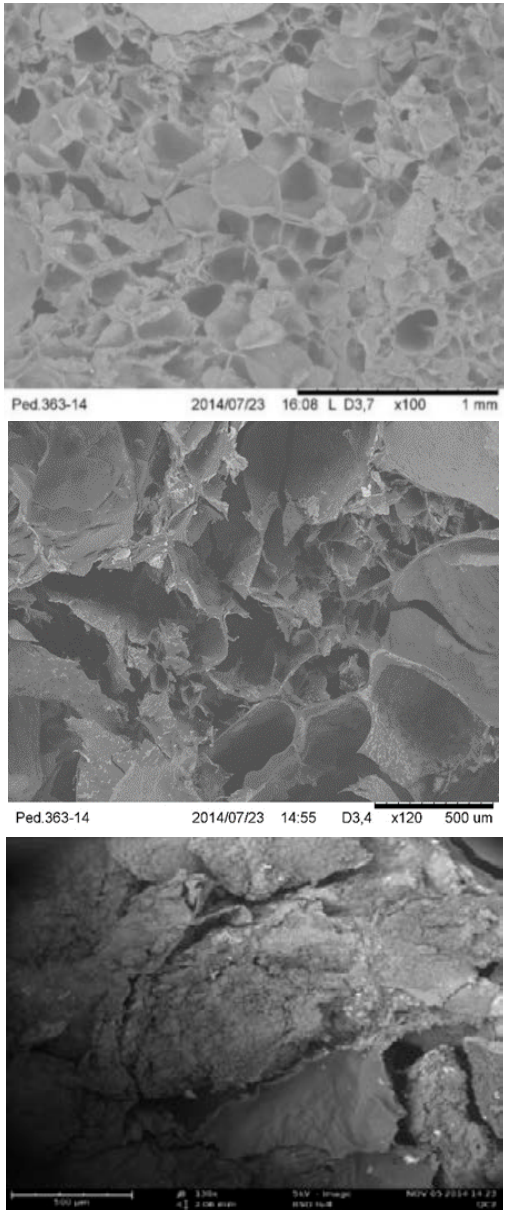

Figura 3: Micrografias na região (a) externa do scaffold quitosana (400x), (b) superfície de fratura scaffold quitosana (100x), (c) externa scaffold quitosana/curcumina (120x), (d) superfície de fratura scaffold quitosana/curcumina (120x), (c) externa scaffold quitosana/curcumina (adsorção) (300x), (f) superfície de fratura scaffold quitosana/curcumina (adsorção) (130x).

A Fig. 4 mostra os resultados obtidos pelas análises de Calorimetria Exploratória Diferencial da quitosana, do scaffold de quitosana, da curcumina, scaffold de quitosana/curcumina, sulfato de sódio em pó e scaffold de quitosana/curcumina (adsorção).

A partir da curva DSC da quitosana é possível visualizar a presença de um pico endotérmico e um pico exotérmico, sendo o pico endotérmico localizado em aproximadamente $120,5^{\circ} \mathrm{C}$ referente à evaporação de substâncias voláteis, como água ligada as pontes de hidrogênio com os grupos hidroxila da quitosana. Um pico exotérmico localiza-se em $305,8^{\circ} \mathrm{C}$ e corresponde à degradação da quitosana. Porém a partir da curva não é possível observar a Tg e a Tm da quitosana.

A curva do sulfato de sódio foi analisada por DSC com a finalidade de mostrar a sua influência nos scaffolds, portanto observa-se a presença de dois picos endotérmicos, sendo o primeiro de menor intensidade em $219,14^{\circ} \mathrm{C}$ e o segundo em $246,95^{\circ} \mathrm{C}$ apresentando uma maior intensidade de pico.

A partir do termograma do scaffold de quitosana, observa-se os picos endotérmicos em $146,9^{\circ} \mathrm{C}$; $235,5^{\circ} \mathrm{C}$; e $285,53^{\circ} \mathrm{C}$, onde tem-se que o pico endotérmico presente na curva da quitosana em pó foi deslocado para $146,9^{\circ} \mathrm{C}$ sendo atribuída à perda de componentes voláteis ou a possibilidade de relaxamento da cadeia. Os picos endotérmicos em cerca de $235^{\circ} \mathrm{C}$ e $285^{\circ} \mathrm{C}$ provavelmente estão relacionados com as 
interações eletrostáticas entre o polímero e os íons do sulfato. Verifica-se que houve o aumento da temperatura dos picos, quando comparado com o termograma do sulfato de sódio onde os picos característicos do sulfato de sódio foram identificados em 219 e $246{ }^{\circ} \mathrm{C}$ [24,25]. Observa-se também o início de um pico largo exotérmico em aproximadamente $305,09^{\circ} \mathrm{C}$, provavelmente referente à degradação do material. De acordo com Zohuriaan e Shokrolahi 2004 [24], neste estágio em altas temperaturas, ocorre a desidratação, despolimerização e decomposição pirolítica, as quais resultam na formação do $\mathrm{NH}_{3}$.

O termograma da curcumina (Fig. 4), apresenta um pico agudo endotérmico a $172,74{ }^{\circ} \mathrm{C}$ indicando a natureza cristalina do fármaco puro [28,29]. Verifica-se também a entalpia de fusão $(\Delta \mathrm{Hf})=135,7 \mathrm{~J} / \mathrm{g}$. É possível observar um pico exotérmico, que começa em aproximadamente $199,5^{\circ} \mathrm{C}$, indicando o início da sua decomposição térmica. Kaewnopparat et al., 2009 [22], estudou algumas proporções de curcumina/Polivinilpirrolidona (K-30), com o objetivo de aumentar a solubilidade e a dissolução da curcumina, e obteve também pela técnica de DSC o pico endotérmico da curcumina em pó a $181,4{ }^{\circ} \mathrm{C}$ e a entalpia de fusão $(\Delta \mathrm{Hf})$ de $119,8 \mathrm{~J} / \mathrm{g}$. A partir do perfil da curva de DSC do scaffold de quitosana/curcumina, Fig. 4, tem-se a presença de três picos endotérmicos, sendo o primeiro a $138,7^{\circ} \mathrm{C}$, o segundo pico em aproximadamente em $234,4^{\circ} \mathrm{C}$ e o terceiro em $278,8^{\circ} \mathrm{C}$, como descrito anteriormente o primeiro pico é apresentado devido à perda de componentes voláteis, e o segundo refere-se as interações eletrostáticas da quitosana com os íons sulfato, e o terceiro pico refere-se a degradação da amostra que tem início em $310,4^{\circ} \mathrm{C}$. Podemos observar que a presença da curcumina, no scaffold de quitosana/curcumina, proporcionou a redução da intensidade do pico endotérmico e por consequência da quantidade de energia necessária para romper os cristais, comparando com a amostra do scaffold de quitosana. Sendo a entalpia de fusão $(\Delta \mathrm{Hf})$ da quitosana/curcumina de 152,5 J/g, e do scaffold de quitosana de 272,9 J/g. Essa mudança na entalpia da amostra com a introdução da curcumina, indica que houve uma alteração da estrutura dos cristais, ocorridas ao nível molecular, indicando assim a perda de cristalinidade da estrutura com a incorporação do fármaco. Verifica-se também total desaparecimento do pico de fusão característico da curcumina. Indicando assim, que a curcumina foi essencialmente encapsulada na quitosana no estado amorfo, ou seja, provavelmente ocorreu a formação de uma mistura sólida homogênea do biopolímero com o fármaco, onde a curcumina encontra-se no interior das partículas conforme relatado por [28, 25]. Porém não é possível identificar a Tg do material no termograma.

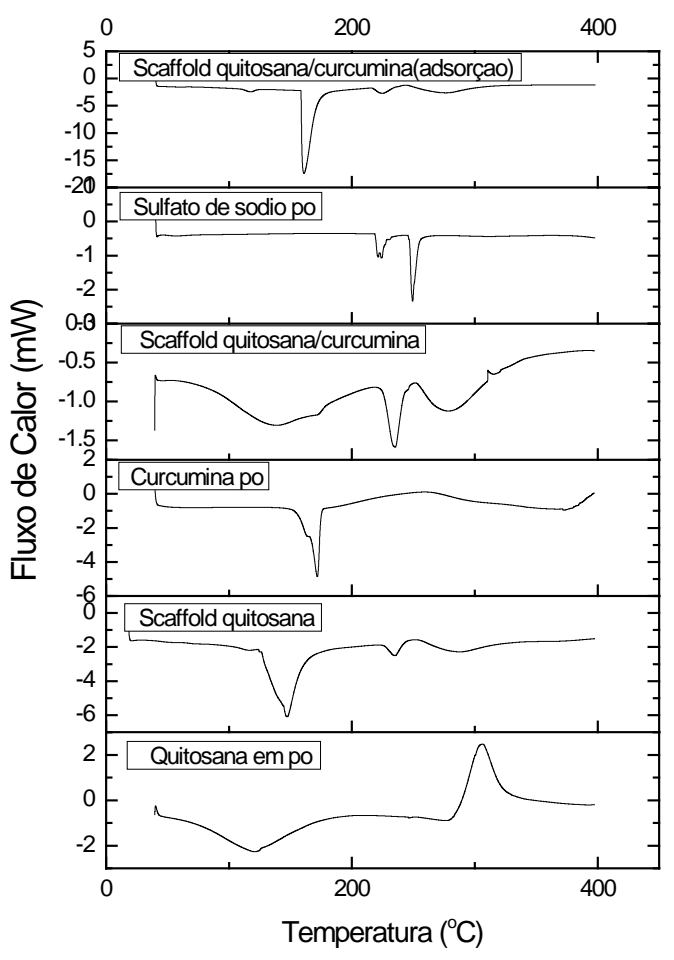

Figura 4: Termograma da quitosana, do scaffold de quitosana, da curcumina, scaffold de quitosana/curcumina, sulfato de sódio em pó e scaffold de quitosana/curcumina (adsorção). 
Na curva DSC para os scaffolds de quitosana/curcumina (adsorção), obtidas pelo método de adsorção, (Fig. 4) tem-se a presença de quatro picos endotérmicos. Sendo o primeiro em $117^{\circ} \mathrm{C}$ característico da desumidificação, o segundo pico está localizado em aproximadamente $160^{\circ} \mathrm{C}$, sendo este pico agudo e de grande intensidade referente do padrão da curcumina. Observa-se que este pico foi deslocado para temperatura menor, pois na curva da curcumina, este pico encontra-se em volta de $170^{\circ} \mathrm{C}$. $\mathrm{O}$ terceiro pico referente a interação eletrostática da quitosana com a curcumina, e o quarto pico referente ao início da degradação do material. Tem-se que a entalpia de fusão ( $\Delta \mathrm{Hf}$ ) da quitosana/curcumina (adsorção) é de 395,7 $\mathrm{J} / \mathrm{g}$, sendo bem maior que as apresentadas pelas amostras de quitosana e de quitosana/curcumina obtidas pelo método de soluções, indicando assim um aumento na cristalinidade da amostra, haja visto que quanto maior a área do pico, maior a entalpia de fusão e por consequência maior a cristalinidade do material. Provavelmente o maior valor de entalpia de fusão alcançado para a amostra de quitosana/curcumina (adsorção), ocorreu devido à presença dos cristais do fármaco na superfície da esfera, conforme visto pela Microscopia Ótica.

Portanto tem-se que pelo método de adsorção, o fármaco não se encontra apenas no interior da esfera de quitosana, mas verifica-se também a presença dos cristais de curcumina na superfície, o que provavelmente ocasionará uma maior facilidade no processo de liberação, quando comparada com a amostra de quitosana/curcumina.

\section{CONCLUSÃO}

Ambos os métodos de inclusão do fármaco nos sistemas de quitosana confirmam que a incorporação e a interação do fármaco com a matriz polimérica (quitosana) alterou as propriedades térmicas e morfológicas dos scaffolds. Verificou-se também que os dois métodos avaliados possibilitaram a obtenção de scaffolds de quitosana/curcumina promissores para o estudo de liberação controlada de fármaco, uma vez que o fármaco se encontra presente no seu interior. Porém com relação ao sistema de quitosana/curcumina (adsorção), observou-se por Microscopia Ótica que este apresentou uma menor aderência entre as partículas, o que provavelmente ocasionará em uma menor resistência compressiva da estrutura.

\section{AGRADECIMENTOS}

À Coordenação de Aperfeiçoamento de Pessoal de Nível Superior/CAPES, Hospital Samaritano de São Paulo e ao Ministério da Saúde do Brasil.

\section{BIBLIOGRAFIA}

[1] CUI, Z., NELSON, B., PENG, Y., et al. "Fabrication and characterization of injection molded poly ( $\varepsilon-$ caprolactone) and poly ( $\varepsilon$-caprolactone)/hydroxyapatite scaffolds for tissue engineering”, Materials Science and Engineering C., v.32, n.6, pp.1674-1681, 2012.

[2] MITSUISHI, M., CAO, J., BÁRTOLO, P., et al., "Biomanufacturing”, CIRP Annals - Manufacturing Technology, v.62, n.2, pp.585-606, 2013.

[3] BERNER, A., WOODRUFF, M.A., LAM, C.X.F. "Effects of scaffold architecture on cranial bone healing", International Journal of Oral and Maxillofacial Surgery, v.43, n.4, pp. 506-513, 2014.

[4] LIU, C., XIA, Z., CZERNUSZKA, J. T. "Design and development of three-dimensional scaffolds for tissue engineering”, Chemical Engineering Research and Design, v. 85, n.7, pp.1051-1064, 2007.

[5] WALTERS, B.D., STEGEMANN, J.P. "Strategies for directing the structure and function of threedimensional collagen biomaterials across length scales”, Acta Biomaterialia, v.10, n.4, pp. 1488-1501, 2014.

[6] ROLANDI, M., ROLANDI, R. "Self-assembled chitin nanofibers and applications", Advances in Colloid and Interface Science, v. 207, pp.216-222, 2014.

[7] HUANG, Y., KUO, T. "O-carboxymethyl chitosan/fucoidan nanoparticles increase cellular curcumin uptake”, Food Hydrocolloids, pp. 1-9, 2015.

[8] LAUS, R., LARANJEIRA, M. C. M., MARTINS, A. O., et al, "Microesferas de quitosana reticuladas com tripolifosfato utilizadas para remoção da acidez, ferro(III) e manganês(II) de águas contaminadas pela mineração de carvão”, Química Nova, v.29, pp. 34-39, 2006.

[9] JAYAKUMAR, R., PRABAHARAN, M., KUMAR, P.T. S., et al. "Biomaterials based on chitin and chitosan in wound dressing applications", Biotechnology Advances., v. 29, n. 3, p.. 322-337, 2011.

[10] MENDES, A. A., OLIVEIRA, P. C. DE., CASTRO, H. F., et al. "Aplicação de quitosana como suporte de para uma imobilização de enzimas de interesse industrial", Química Nova, v. 34, n.5, 2011. 
[11] DASH, M., CHIEllini, F., OTTEnBRITE, R.M., et al. "Progress in Polymer Science. Chitosan-A versatile semi-synthetic polymer in biomedical applications”, Biomaterials, v.36, n.8, pp. 981-1014, 2011.

[12] THEIN-HAN, W. W., MISRA, R. D. K. "Biomimetic chitosan-nanohydroxyapatite composite scaffolds for bone tissue engineering", Acta Biomaterialia, v.5, n.4, pp. 1182-1197, 2009.

[13] VILlANOVA, J. C. O., ORÉFICE, R. L., CUNHA, A. S. "Aplicações Farmacêuticas de Polímeros", Polímeros: Ciência e Tecnologia, v.20, n.1, pp.51-64, 2010.

[14] CHUAH , L. H., ROBERTS , C. J., BILLA, N., et al., "Cellular uptake and anticancer effects of mucoadhesive curcumin-containing chitosan nanoparticles", Colloids and Surfaces B: Biointerfacs, v. 116, p. 228-236, 2014.

[15] LYRA, M.A.M., SOARES-SOBRINHO, J. L., BRASILEIRO, M. T., et al., "Sistemas Matriciais Hidrofílicos e Mucoadesivos para Liberação Controlada de Fármacos", Latin American Journal of Pharmacy, v.26, n.5, pp. 784-93, 2007.

[16] BAJPAI, S. K., CHAND, N., AHUJA, S. "Investigation of curcumin release from chitosan/cellulose micro crystals (CMC) antimicrobial films”, International Journal of Biological Macromolecules, v.79, n. p.440-448, 2015.

[17] LI, J., SHIN, G. H., LEE, IL W., et al. "Soluble starch formulated nanocomposite increases water solubility and stability of curcumin”, Food Hydrocolloids, v. 56, p.41-49, 2016.

[18] ARAUJO, C. A. C., LEON, L. L. "Biological Activities of Curcuma Longa L”, Memórias do Instituto Oswaldo Cruz, v.96, n.5, pp.723-728, 2001.

[19] BEPPU, M. M., ARRUDA, E. J., SANTANA C. C. "Síntese e Caracterização de Estruturas Densas e Porosas de Quitosana", Polímeros: Ciência e Tecnologia, v.9, n.4, pp. 163-169, 1999.

[20] SOUZA, K. V., ZAMORA, P. G. P., ZAWADZKI, S. F. “Esferas de Quitosana/Fe na Degradação do Corante Azul QR-19 por Processos Foto-Fenton Utilizando Luz Artificial ou Solar”, Polímeros: Ciência e Tecnologia, v.20, n.3, pp. 210-214, 2010.

[21] SAMPATH, M., LAKRA, R., KORRAPATI, P., et al.,"Curcumin loaded poly (lactic-co-glycolic) acid nanofiber for thetreatment of carcinoma", Colloids and Surfaces B: Biointerfaces, v.117, pp.128-134, 2014.

[22] KAEWNOPPARAT, N., KAEWNOPPARAT, S., JANGWANG, A., et al. "Increased Solubility, Dissolution and Physicochemical Studies of Curcumin-Polyvinylpyrrolidone K-30 Solid Dispersions”, World Academy of Science, Engineering and Technology, v.31, 2009.

[23] ANITHA, A., MAYA, S., DEEPA, N., et al., "Efficient water soluble O-carboxymethyl chitosan nanocarrier for the delivery of curcumin to cancer cells", Carbohydrate Polymers, v.83, pp.452-461, 2011.

[24] CHEN, J., DAI, W.T., HE, Z.M, et al. "Fabrication and evaluation of curcumin-loaded nanoparticles based on solid lipid as a new type of colloidal drug delivery system", Indian Journal of Pharmaceutical Sciences, v.75, n.2, pp.178-184, 2013.

[25] ZOHURIAAN , M.J., SHOKROLAHI, F., "Thermal studies on natural and modified gums", Polymer Testing, v.23, n.5, pp. 575-579, 2004.

[26] YALLAPU, M. M., JAGGI, M., CHAUHAN, S. C. “ $\beta$-Cyclodextrin-curcumin self-assembly enhances curcumin delivery in prostate cancer cells”, Colloids and Surfaces B: Biointerfaces, v.79, n.1, pp. 113-125, 2010.

[27] PARIZE, A. L., STUlZER, H. K., LARANJEIRA, M. C. M., et al., "Evaluation of chitosan microparticles containing curcumin and crosslinked with sodium tripolyphosphate produced by spray drying", Química Nova, v.35, n.6, pp.1127-1132, 2012.

[28] YADAV, A., LOMASH, V., SAMIM, M., et al. "Curcumin encapsulated in chitosan nanoparticles: A novel strategy for the treatment of arsenic toxicity”, Chemico-Biological Interactions, v. 199, n.1, p. 49-61, 2012.

[29] MOHAN, P.R. K., SREELAKSHMI, G., MURALEEDHARAN, C.V., et al. "Water soluble complexes of curcumin with cyclodextrins: Characterization by FT-Raman spectroscopy”, Vibrational Spectroscopy, v. 62, p.77-84. 2012. 